\title{
A GIS-based Subcatchments Division Approach for SWMM
}

\author{
Shen Ji and Zhang Qiuwen*
}

\begin{abstract}
College of Hydropower and Information Engineering, Huazhong University of Science and Technology, Wuhan, Hubei, 430074, P.R. China
\end{abstract}

\begin{abstract}
Storm Water Management Model (SWMM) is a digital hydrological model which is widely used for the simulation of rainfall-runoff processes in urban catchment. SWMM is a distributed model, which means a study urban catchment needs to be divided into several irregular subcatchments first before simulation. However, most of the existing subcatchments division approaches for the SWMM are not able to capture the characteristics of the spatial variability in topography and hydro information of urban catchment. In this paper, a new subcatchment-division approach for SWMM is proposed. Two existing division method are combined together in this approach by using Geographic Information System (GIS), which can make the subcatchments fully reflect the hydrological features of the urban catchment, thus further improve the simulation results of SWMM. The actual application results show that the SWMM using the subcatchment dividing by the approach in this paper is more reliable than other existing SWMM in urban region.
\end{abstract}

Keywords: DEM, GIS, roads conduits and junctions, spatial analysis, subcatchments division, SWMM, urban catchment, urban rainfall-runoff process.

\section{INTRODUCTION}

In recent years, due to the serious threats from the storm water disasters to the traffic, commerce, production and lives and properties of citizens, it is very important to establish scientific methods for urban storm water disaster prevention and control [1]. SWMM is one of the most important methods in urban storm disaster prevention researches, which can describe the rainfall-runoff processes of the rainstorm and provide a strong data support to the flood risk evaluation [2], lose assessment [3] and disaster forecast research [4]. In SWMM, the urban region is divided into smaller computational units which have own hydrological characteristics and independent rainfall-runoff processes, called subcatchments. According to the spatial distribution of these subcatchments, all the hydrological and geographical information is collected and imported into the SWMM, on the basis of which the simulation can be carried out. Thereby, the results in subcatchments dividing will directly affect the output of SWMM [5], it is quite important for us to propose a reliable subcatchments dividing approach and capture the effect that spatial variability in topography, land cover and hydro information have on runoff generation.

Currently, there are mainly two types of commonly used approaches for the subcatchments dividing in SWMM.

The first one is the approach based on the subwatersheds partition method [6]. Subwatershed is the distribution units of the natural distributed hydrological model. The hydro processes inside each subwatershed are independent, which can well reflect the spatial no uniformity of hydrological characteristics in each watershed. As the subcatchment in the SWMM plays a similar role as the subwatershed in natural distributed hydrological model. The partition method of subwatershed is always applied in the SWMM for subcatchment division. This method has a good physical basis, but the shortcoming is also obvious in the urban region. In this method, the flow direction of the watershed need to be first calculated on the basis of Digital Elevation Model (DEM) data. However, due to the large range of flat terrain, it is always difficult to get the flow direction of the urban storm watershed. Moreover, as there is no correlation between division results and the distribution of the drainage system of the city, it is difficult to determine the outlet of each subcatchment, which is usually composed of junctions or another subcatchment in SWMM.

The second approach is based on the drainage system [7]. As the junctions in the drainage system of the city are always considered as the outlets of the subcatchments in SWMM, in this approach, the study area is divided into several subcatchments according to the drainage area of each junction. By using the Thiessen polygon method, the drainage areas can be determined on the basis of the spatial distribution of the junctions. This approach is quite simple and feasible, which make it widely adopted in the existing application of SWMM. For each subcatchment in this approach, the junction of the corresponding Thiessen polygon is set to be the outlet, and the all the storm water of subcatchment will finally flow to it. However, as this approach is only based on the geometry method, the topography condition of the catchment is not considered in the division processes, the actual flow direction inside each subcatchment may not be the same with that in Thiessen polygon. The distortion in the distribution of drainage area will definitely affect the accuracy of the SWMM, and reduce the reference value of the simulation result in the disaster prevention works. 
Apparently, there are several shortcomings in both two subcatchments dividing approaches above. The main reason of these shortcomings lies in that the urban catchment is the combination of natural terrain and artificial drainage facilities, and all of the existing dividing methods are based on only one of them. In this paper, according to the characteristics of the rainfall-runoff processes in the urban region, the two subcatchments dividing approaches are combined together by using the GIS technology, and then a new approach is proposed. In this approach, the effects of surface topography, roads and conduits, junctions and buildings on the rainfall-runoff processes are all reflected in the distribution of subcatchment, which can make the SWMM model more typical and reliable.

\section{GIS-BASED SUBCATCHMENTS-DIVISION AP- PROACH FOR SWMM}

\subsection{The Characteristics of Rainfall-runoff Processes in the Urban Catchment}

As the subcatchment is actually the calculation cell of surface rainfall-runoff simulation in SWMM, the partition approach of subcatchment is inseparable from the overland runoff and flow processes of the urban catchment. Compare with the natural watershed, the runoff processes in urban region has their own hydrological characteristics:

1. The underlying surface cover types of urban catchment are complex and spatial heterogeneous, which will change with the development and construction of the city and further affect the runoff parameters of the urban surface [8];

2. The region of urban catchment always has a small degree of topographic relief and average slope. As a result, it is difficult to extract any explicit water system or river network directly from the topographic relief of the urban region;

3. Roads and conduits network is the main paths of the surface and underground flow of the storm water for some local urban regions, which play an important role in the process of rainfall-runoff in the urban catchment [9];

4. There are always high densities of residential and commercial buildings distributed on the surface of urban catchment, which will block the flow path and change the flow directions of the storm runoff water, and thus significantly affect the processes of rainfall-runoff and overland flow in the urban region.

\subsection{General Division Method of the New Subcatchments- division Approach}

According to the characteristics of rainfall-runoff processes in the urban catchment, it can be inferred that the roads and conduits network is the actual flow path of the storm runoff, which is similar to the river network in the nature watershed. Therefore, all the roads and conduits can be considered as rivers in the urban catchment, and the drainage areas of them, which have own hydrological characteristics and independent rainfall-runoff processes, are actually the calculation cells of SWMM. In the new subcatchments division approach proposed in this paper, the drainage areas of roads and conduits are chosen to be the subcatchments of the SWMM.

As the overland runoff and flow processes are also closely related to the topography condition of the urban surface, the division method for drainage areas in the traditional approach which only consider the spatial distribution of roads and conduits is not suitable for the new approach in this paper. On the other hand, in the subwatersheds partition method that is widely used in nature watershed, the terrain information is fully considered in the division method based on the DEM data, which can provide a good physical basis for the division results. In this paper, the drainage area of each road and conduit is extracted from the DEM by using subwatersheds partition method [10]. In order to combine the natural terrain and artificial drainage facilities of the urban catchment together, GIS technology is introduced into the division approach, and the origin DEM data is adjusted by the distribution features of the roads, conduits and builds on the basis of spatial analysis method [11]. In this way, the hydrological characteristics of the runoff and flow processes can be well reflected by the adjusted DEM data and the flow calculation results.

\subsection{DEM Adjustment Method of the Subcatchment- division Approach}

In the subwatersheds partition method, the flow directions of the surface need to be firstly calculated on the basis of the DEM data. However, according to the characteristics of runoff and flow processes in the urban catchment, it is difficult to calculate the flow direction because of the flat topography. Moreover, as the actual runoff and flow processes in urban region are not just influenced by the topography condition, but also closely related to the spatial distribution of roads, conduits and buildings, the original DEM data without them is no longer adaptable for the flow direction algorithm of urban region. In order to combine natural terrain with the distribution of roads, conduits and buildings, a GIS based DEM adjustment method is designed in this paper, which can not only remove the flat area that located in urban catchment, but also make storm water flow toward the drainages and away from the buildings under the action of gravity.

\subsubsection{Roads and Conduits Adjustment}

In the urban storm watershed, the ideal surface runoff mode is all the storm water flow to the nearest road by the overland flow, and finally enters into the drainage system from junctions on the ground. In order to embody the processes above in the DEM data, according to the spatial distribution of the roads and conduits, the DEM data are modified based on the overlay and buffer analysis function in GIS. Take the conduits adjustment for example, the adjusting steps of it is shown in the Fig. (1).

1. Convert the conduits data from polyline feature layer to raster layer, and overlay the converted conduits layer to the DEM layer in order to get the collection of DEM pixels where the conduits are located;

2. Reduce the elevation values of the DEM pixels in the collection by using the formula: 

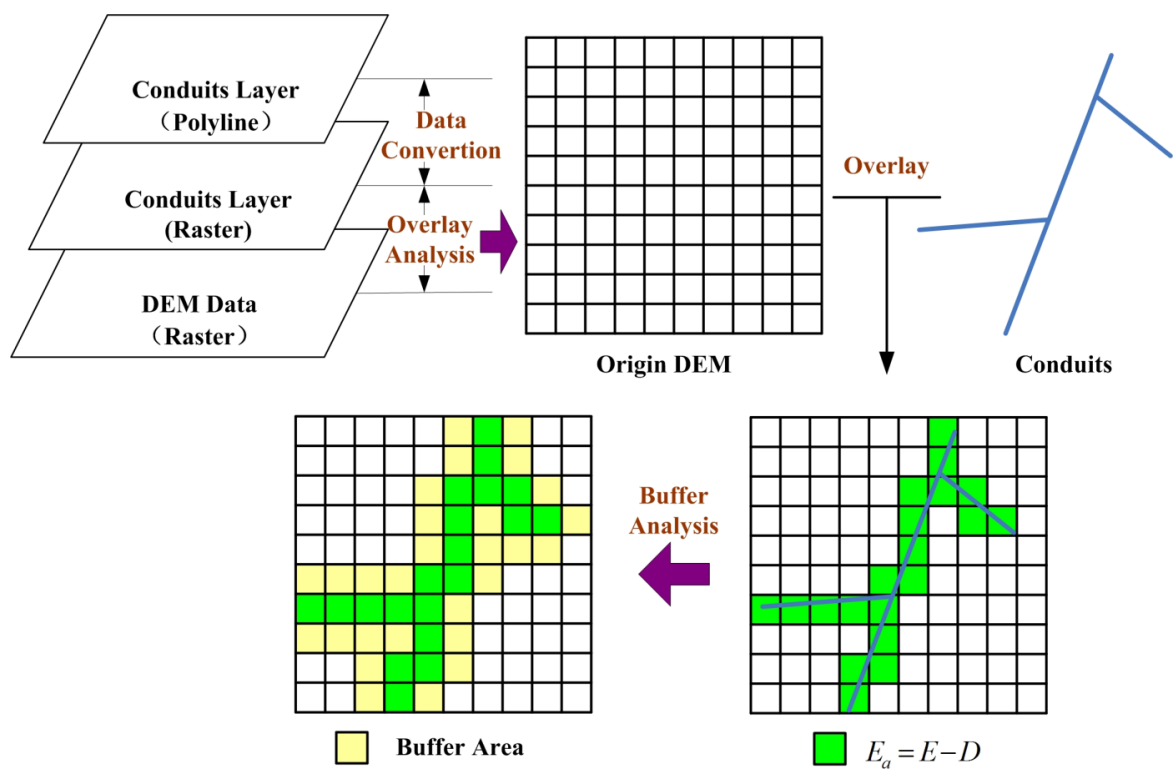

Fig. (1). Roads and conduits adjustment.

$E_{a}=E_{i}-D$

where,

$E_{i}$---the original elevation of the pixel;

$E_{a}$---the adjusted elevation of the pixel;

$D$---the burial depths of the conduits which the DEM pixels intersect with.

3. Using the buffer analysis to calculate the buffer area of the conduits for a certain distance, and get the collection of DEM pixels in buffer area;

4. Reduce the elevation values of the DEM pixels in the collection according to the distance from each pixel to the conduits, the closer the pixel to the conduits, the larger the decrease value is.

In this way, due to the deep burial depth of the trunk conduits, the elevation of DEM pixels of these conduits are decreased in greater degree, which form trunk river system in the DEM data. Similarly, for the branch conduits, by DEM adjusting it can form branch river system. After adjustment, the rainwater will gather at the roads and conduits systems and flow along them, which is more accordance with the actual runoff processes in the urban region.

\subsubsection{Buildings Adjustment}

The buildings distributed in the urban storm watershed will hinder the surface runoff flow of the rain water. As a result, the flow direction will not point to the DEM pixels where the buildings are located in general conditions. In the DEM adjustment method, these DEM pixels are considered as highlands with high elevations. By using the spatial overlay analysis tool of the GIS, these DEM pixels are adjusted by the following steps in Fig. (2):

1. Convert the buildings data from point or polygon feature layer to raster layer, and overlay the buildings layer to the DEM layer in order to get the collection of DEM pixels where the buildings are located;

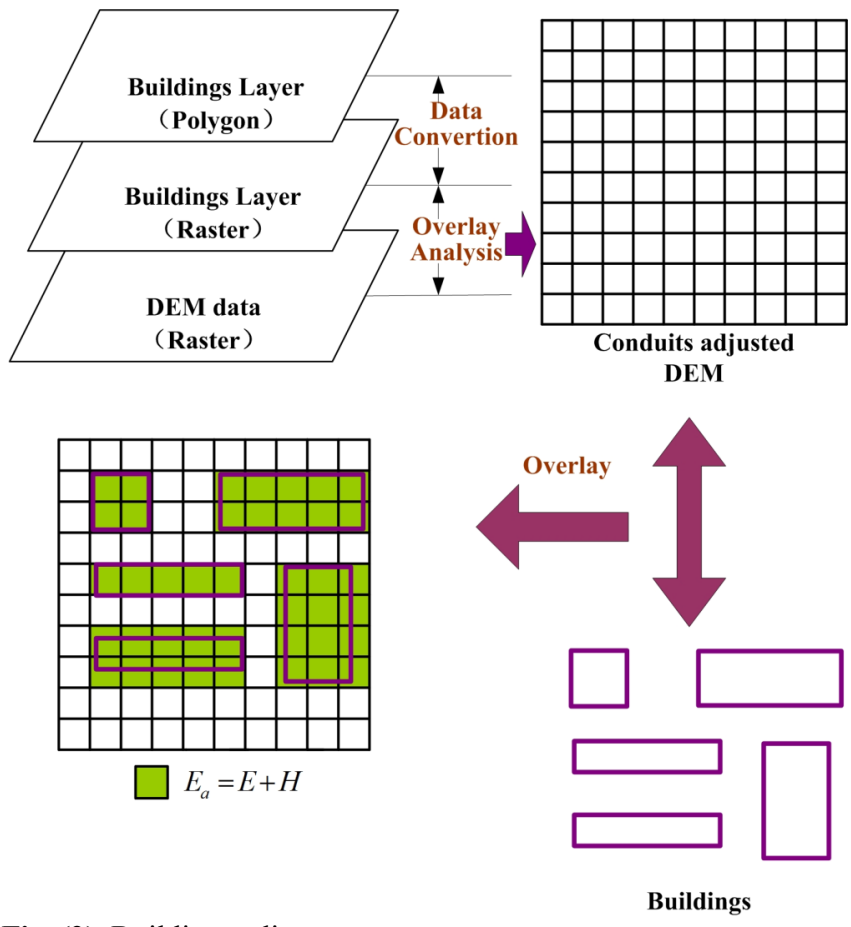

Fig. (2). Buildings adjustment.

2. Reduce the elevation values of the DEM pixels in the collection by using the formula:

$E_{a}=E_{i}+H$

where,

$H$---the heights of the buildings which the DEM pixels intersect with.

In this way, the rainwater whether from the adjacent pixels or accepted by the pixels themselves will flow away from the buildings at normal rainfall conditions. In the extreme rainfall, as low buildings may be entirely submerged in the storm water, the corresponding DEM pixels of these building may become the runoff path of the storm water again, which is same with the actual situations in the urban region. 


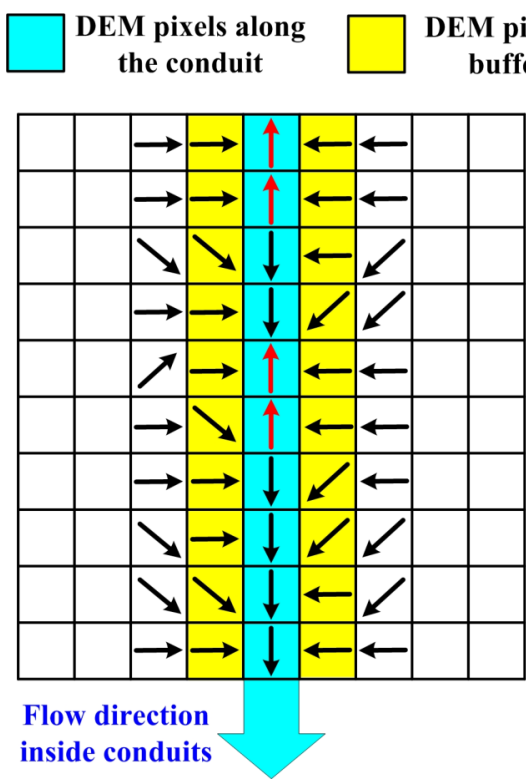

Fig. (3). Flow direction adjustment.

\subsubsection{Flow Direction Adjustment}

After the DEM data adjustments are finished, the flow direction can be calculated by using the $\mathrm{D} 8$ algorithm [12]. As the adjusted DEM data not merely reflect the spatial distribution of artificial drainage facilities but also reserve the original physical features of the urban catchment, the rain water from the DEM pixels that on both sides of the roads and conduits will flow to the DEM pixels where these drainage facilities are located. In the roads and conduits adjustment, as the DEM data are modified based on burial depths of the conduits, elevation of the DEM pixels that along the same conduit are decreased by the same value. As a result, the adjustment procedures cannot change the terrain fluctuation of the areas along each road or conduit, which will lead to some degrees of distortion in the flow direction calculation results of these areas. In order to solve this problem, this paper provide an further adjustment for the flow direction results of the DEM pixels along every road and conduit based on the actual water flow direction of them, as shown in Fig. (3).

After adjustment, the flow direction of each DEM pixels is consistent with the actual runoff process of the urban surface, which can provide a scientific data reference for the division of subcatchments.

\subsection{Subcatchments Division and Coding}

In the subwatersheds partition method that using in traditional distributed hydrological model, after the flow direction of the urban surface have been determined, the subwatershed of each river can be extracted by collecting all the DEM pixels with flow direction finally point to the pixels of rivers. For the subcatchment-division approach proposed in this paper, as the roads and conduits are considered as the rivers in the urban catchment, and the drainage area of each road and conduit is taken as a subcatchment in the SWMM which has a similar physical meaning with the sub-watershed of each river, so we can extract the drainage area by using subwatersheds partition method. According to the DEM pixels collection of each road and conduit, the drainage areas of the roads and conduits are determined, as shown in Fig. (4).

After extraction, the DEM pixel collection of each drainage area can be converted into an irregular polygon feature, which represents the spatial geometry figure of each subcatchment. All the polygon features of the entire urban catchment can be concentrated and stored as a polygon layer. The hydrological data of urban storm water can be collected and stored in the attribute data table of subcatchment layer by using the spatial analysis and statistic method in GIS. As there is a one to one relationship between each subcatchment and road or conduit, the code to identify each subcatchment can be set as the same value with the code of its corresponding road or conduit. Thereby, we can easily get the corresponding road, conduit and junctions or any other hydrological information of each subcatchment only according to the code of it.

\section{CASE STUDY OF THE SUBCATCHMENT DIVI- SION APPROACH}

In order to validate the feasibility, the subcatchmentdivision Approach that proposed in this paper is implemented by applying secondary development to the software platform of ArcGIS, using the VBA programming. A study area which is located in the middle region of China is selected and divided into several subcatchments by using the division approach in this paper.

\subsection{Study Area}

The study area is the campus of a university that is located in the city of Wuhan, China. The campus covers a total area of 2.27 square kilometers, the land use types mainly include urban land, afforested cover and shrub cover, and there is no significant nature water system in the experimental region. According to the DEM data, the campus is generally flat that with little gradient in the south, but hilly in the 


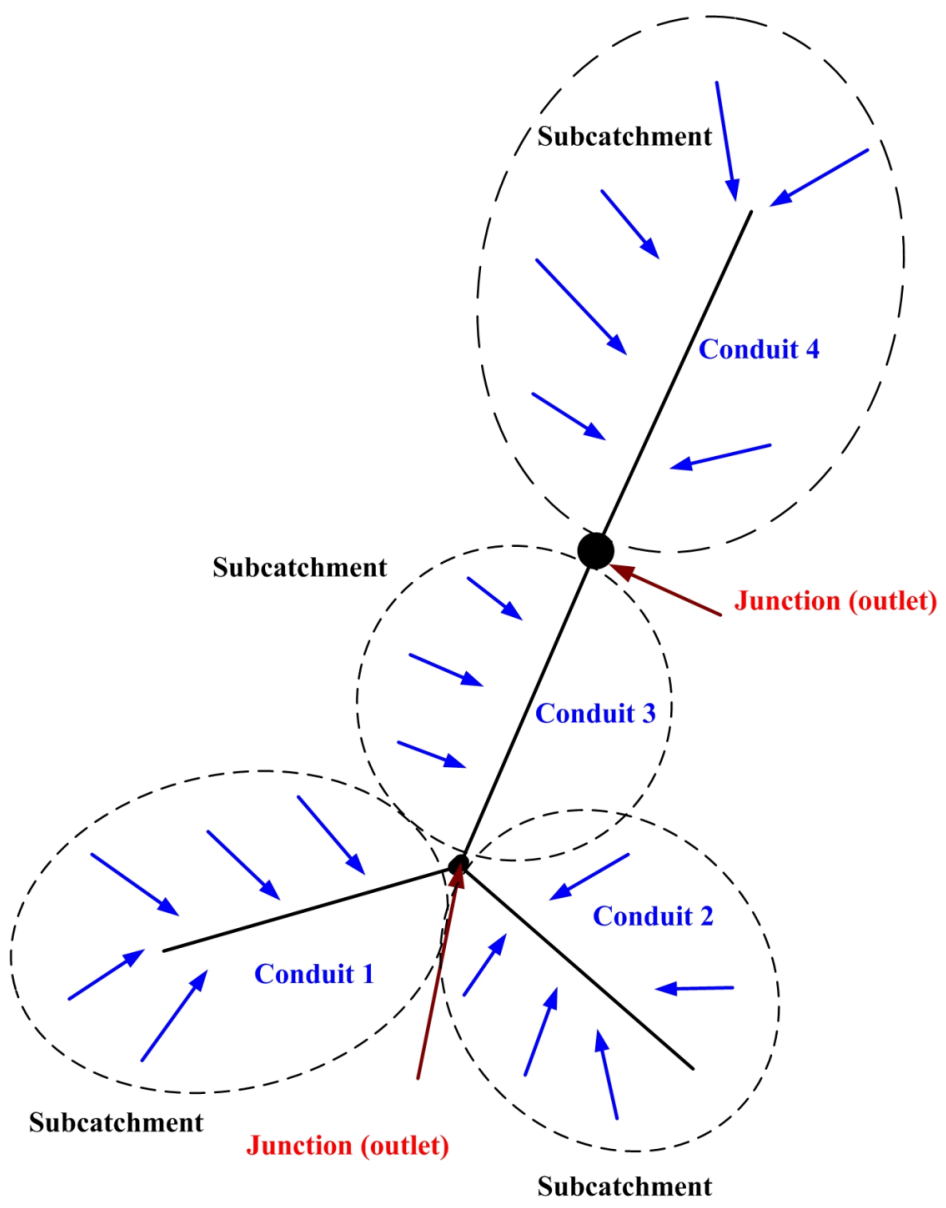

Fig. (4). Extracting subcatchment from DEM data.

north, and the range of its elevation is between $24 \mathrm{~m}$ to $147 \mathrm{~m}$. The drainage facilities in the campus are complete but aging in a certain degree. In July 2013, a torrential rain in Wuhan caused serious storm water logging in the west of the campus, which severely threatened the safety and property of students. As a result, there is practical value and representative to select this area as the study area of the partition approach in this paper.

\subsection{Subcatchment Division and Coding Results for the Study Area}

According to the spatial distribution of roads, conduits and buildings in the study area, the DEM data is adjusted and the flow direction is calculated by D8 algorithm. On the basis of flow direction results, the study area is divided into 24 drainage areas, which form the spatial polygon layer of subcatchment, as shown in Fig. (5).

\subsection{Hydrological Information Collecting and Storing for the SWMM}

After the spatial geometry figure of each subcatchment is determined, all the hydrological information inside it can be collected and stored in the attribute table of the subcatchment layer, the statistical measures from the hydrological parameters of each subcatchment in the study area are given in the Table 1.

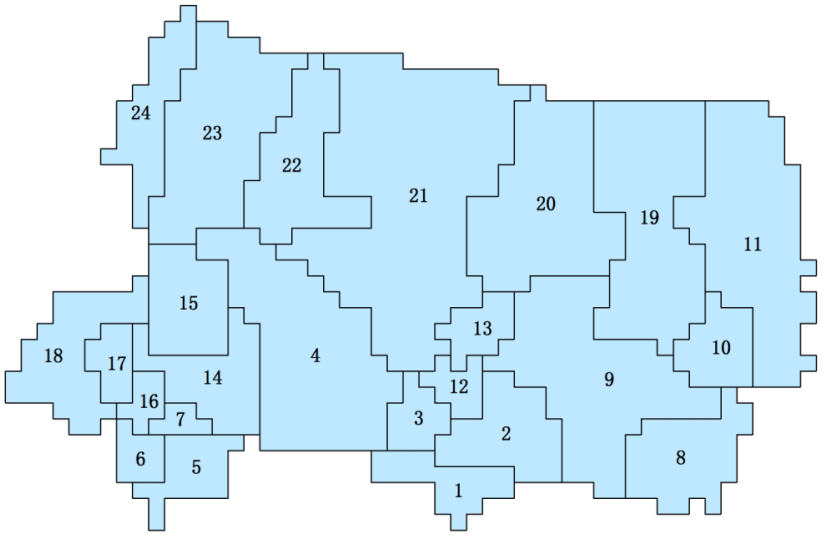

Fig. (5). The Subcatchment-division and Coding Result of Study Area.

As shown in Table 1, the areas of subcatchments in the study area are between $26.45 \mathrm{ha}$ and $1.25 \mathrm{ha}$, the advantage area out of 24 subcatchments is approximately 9.49 ha. Due to the flat topography in the study area, the mean slopes of subcatchments are between $4.2 \%$ and $0.2 \%$.

\subsection{The Simulation Results from the SWMM Based on the Subcatchments Division Approach in this Paper}

After all the hydrological parameters for the SWMM are calibrated and stored in the attribute records, the subcatch- 
Table 1. The statistical measures form the hydrological parameters of each subcatchment.

\begin{tabular}{|c|c|c|c|}
\hline Parameter & Max Value & Mean Value & Min Value \\
\hline \hline Area $(h a)$ & 26.45 & 9.49 & 3.25 \\
\hline Mean Elevation $(m)$ & 77.79 & 50.5 & 0.2 \\
\hline Mean Slope & 4.2 & 1.27 & 29.87 \\
\hline Width $(m)$ & 368.09 & 109.23 & 0 \\
\hline Impervious Percent(\%) & 100 & 54.78 & 0.011 \\
\hline Manning's N for Imperv & 0.015 & 0.0144 & 0.2 \\
\hline Manning's N for Perv & 0.27 & 0.21 & 5.08 \\
\hline Dstore for Perv $(m m)$ & 5.97 & 5.17 & \\
\hline
\end{tabular}

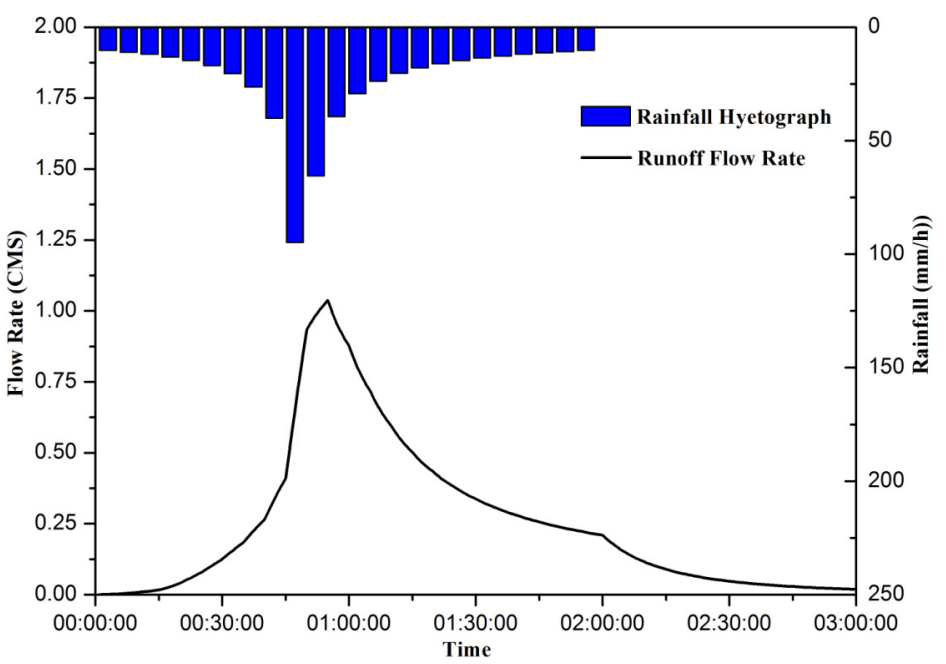

Fig. (6). The runoff flow rate curve of subcatchment no.18 that simulated by the SWMM.

ments of the study area can be applied to the urban rainfallrunoff modeling in SWMM. A rainstorm with the parameters close to the heavy rainfall event in July 2013 is designed in this study. According to the rainfall statistical data of the study area, the return period of the rainstorm in July 2013 is 5 years, on the basis of return period and formula of rainstorm intensity, the instantaneous hyetograph with $120 \mathrm{~min}$ as rainfall duration and $5 \mathrm{~min}$ as time step is given. Fig. (6) shows the runoff flow rate curve of subcatchment No.18 with the designed rainstorm as input.

In Fig. (6), the max value of the runoff flow rate in subcatchment reaches over $1.04 \mathrm{CMS}$, which appeared at 55 minutes after the rainfall started. It can be inferred that the varying trend of runoff flow rate is consistent with the rainfall hyetograph, which indicates that as the characteristics of natural terrain and artificial drainage facilities are considered in the subcatchments division approach in this paper, the simulation results in SWMM based on it are able to reflect the surface runoff and flow processes of the urban region.

\section{CONCLUSION}

This paper provides a new subcatchments division approach especially for SWMM. In this approach, according to the characteristics of rainfall-runoff and overland flow processes of urban region, the roads and conduits is considered as the main flow path of the runoff water, and the subcatchments of SWMM can be constituted by the drainage areas of roads and conduits. On the basis of distribution information of the artificial drainage facilities in urban region, the DEM data is adjusted by using the spatial analysis method in GIS. Therefore, the flow direction results based on the adjusted DEM could be more realistic. After the flow direction is obtained, the drainage area of each road and conduit can be calculated by collecting all pixels that the flow direction finally point to it, which can form the subcatchments of the SWMM. Finally, the development of the division approach in this paper is finished by the support of ARCGIS platform, a study area and designed rainstorm are determined as well for the case study. The result shows the subcatchments that divided by the division approach in this paper are suit for the hydrological conditions of urban region. More importantly, the implementation of subcatchments division approach in this paper is able to solve the problem of how to reflect the hydrological features in the distribution of subcatchments, which can provides a new ideal for the improvement of the SWMM. 


\section{CONFLICT OF INTEREST}

The authors confirm that this article content has no conflict of interest.

\section{ACKNOWLEDGEMENTS}

The authors would like to appreciate the supports for this study from the National Natural Science Foundation of China (no. 41072199 and 41101258) and the National Key Technology R\&D Program of China (no. 2008BAC36B01).

\section{REFERENCES}

[1] J. Yan, J. Zhang, and X.B. Yang, "Global warming and the optimal utilizing method for urban rain-flood", Advanced Materials Research, vol. 214, pp. 276-280, 2011.

[2] C. Wang, T.R. Wan, and I.J. Palmer, "Urban flood risk analysis for determining optimal flood protection levels based on digital terrain model and flood spreading model", Visual Computer, vol. 26, no. 11, pp. 1369-1381, 2010.

[3] X.S. Liu, and J.Y. Zhang, "Flood loss evaluation based on spatial information grid of socio-economic data", Journal of Applied Sciences, vol. 13, no. 21, pp. 4550-4554, 2013.

[4] S.Y. Liong, W.T. Chan, and C.L. Law, "An expert system for storm water management modeling, and its application", Engineer- ing Applications of Artificial Intelligence, vol. 4, no. 5, pp. 367$375,1991$.

[5] J. Gironas, L.A. Riesner, and L.A. Rossman, "A new applications manual for the Storm Water Management Model (SWMM)", Environmental Modelling \& Software, vol. 25, no. 6, pp. 813-814, 2010.

[6] M.C. Rulli, "A physically based watershed partitioning method", Advances in Water Resources, vol. 33, no. 10, pp. 1206-1215, 2010.

[7] S.R. Abt, C.L. Thornton, and T.L. Johnson, "Estimating drainage area on steep uniform slopes", Water Resources Bulletin, vol. 31, no. 1 , pp. 53-57, 1995.

[8] N.R. Goodwin, N.C. Coops, and T.R. Tooke, "Characterizing urban surface cover and structure with airborne lidar technology", Canadian Journal of Remote Sensing, vol. 35, no. 3, pp. 297-309, 2009.

[9] D. Ramier, E. Berthier, and H. Andrieu, "The hydrological behavior of urban streets: long-term observations and modeling of runoff losses and rainfall-runoff transformation", Hydrological Processes, vol. 25, no. 14, pp. 2161-2178, 2011.

[10] A. Tribe, "Automated recognition of valley lines and drainage networks from grid digital elevation models: A review and a new method", Journal of Hydrology, vol. 139, no. 1-no. 4, pp. 263-293, 1992.

[11] M. F. Goodchild, "Spatial analysis with GIS: problems and prospects", In: Proceedings of GIS/LIS 91, Atlanta, 1991, pp. 40-48.

[12] J. O. Callaghan, and D. Mark, "The extraction of drainage networks from digital elevation data". Computer Vision Graphics and Image Processing, vol. 28, no. 3, pp. 323-344, 1984. 